\title{
A Tribute to Euryclides de Jesus Zerbini, MD
}

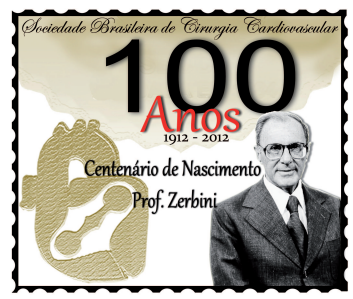

\author{
Ricardo Lima, MD, Fernando A. Lucchese, MD, Domingo M. Braile, MD, and Tomas A. Salerno, MD
}

Faculdade de Ciências Médicas, Universidade de Pernambuco, Recife, Fundação Faculdade Federal de Ciências MedicasSanta Casa, Porto Alegre, RS, Universidade de Campinas (Unicamp), Campinas, São Paulo, and Rio Preto Medical School (FAMERP), São José do Rio Preto, Brazil, and the Division of Cardiothoracic Surgery, University of Miami, Jackson Memorial Hospital, Miami, Florida

Omnia vincit labor.

Euryclides de Jesus Zerbini

The development of cardiac operations in Brazil was an important event in South America. Euryclides de Jesus Zerbini (pictured above) overcame every impediment to lead this endeavor. When heart surgery grew beyond just workmanship and became dependent on technology, Zerbini continued to practice advanced science in a country plagued by health and social problems.

\section{Birth and Education}

Zerbini was born in a modest home in the rural countryside of São Paulo State, Brazil, on May 17, 1912. Born prematurely, the infant Zerbini could fit into a shoebox. As he grew, he decided to take up medicine because of pressure from his father-an elementary school teacher of Italian origin but a naturalized Brazilian who wanted his five children to pursue high positions in life.

Zerbini came to São Paulo in December 1929. He was 17 years old at the time and had graduated first in his class. Entrance into medical school required an examination; only the first 50 candidates were accepted. Zerbini ranked among the top 10. Alone in São Paulo, he knew no one well enough to share his joy of having been admitted into medical school at the University of São Paulo. At that time, the University enjoyed an excellent reputation, supported in part by the Rockefeller Foundation. Studying medicine in São Paulo was not inexpensive, even considering that tuition was free. Zerbini relieved his father's financial burden by teaching chemistry, physics, and natural history during his first year of medical school.

In 1933, Zerbini went to the "São Paulo Santa Casa de Misericordia," one of the most fashionable teaching hospitals in Brazil, where he met the famous surgeon Alipio Correa Netto. Alipio had fought in the Brazilian Expeditionary Force in the Allied campaign in Italy and was the only non-American surgeon authorized to operate on American soldiers. In Alipio, Zerbini found a mentor and source of inspiration that would guide his entire career.

Circumstances led Zerbini to operate on the human thorax. At that time, the heart was still an "anatomical fiction" that could be directly viewed or touched only in the morgue. Thoracic surgeons in the 1930s ventured only near the lungs and, even then, with reservation. Pulmonary surgery, which did not involve direct intervention on the lungs, was primarily for tuberculosis. The sanatoria were full and the only hope for survival for many tuberculosis sufferers was to undergo thoracoplasty.

Operating on tuberculosis patients was almost a social mission, posing grave risks for the surgeon because of the possibility of patient-to-physician contamination.

Zerbini, however, never contracted the disease.

Four years after graduating from medical school, Zerbini was the youngest head of a division at the Medical School of the University of São Paulo. To fill the highly coveted post of first assistant in the discipline, a position immediately below that of full professor, Dr Alipio Correia Netto could have chosen one of his longtime assistants. Surprisingly, he opted to appoint Zerbini to the position. 
At the age of 29, Zerbini took up the senior teaching position at the Medical School of the University of São Paulo. To this end, he studied hard for 1 year to compete for a position that normally required 5 years of preparation. He was required to take oral and written examinations on live and cadaveric operations, and to defend a thesis. The subject chosen for his lecture was supratentorial brain tumors. His score for the examination was 9.41 on a 10 -point scale [1].

\section{The clinical years}

On February $26^{\text {th }}, 1942$, in the "São Paulo Santa Casa de Misericórdia" hospital, Zerbini performed his first heart operation. The patient was a 6-year-old boy who had arrived at the hospital comatose. He had received a wound next to his left nipple caused by a fragment from an anvil while iron was being cast. The boy was dying from cardiac tamponade. Zerbini opened the pericardium, removed the fragment that had injured the anterior wall of the heart and ligated the damaged left anterior descending coronary artery. The case was reported in the Journal of Cardiac Surgery in 1943 in an article entitled "Coronary ligation in wounds of the heart." While technically unremarkable by today's standards, this operation was a tremendous undertaking given the status of cardiac surgery at that time.

Zerbini's main interest, however, remained with pulmonary surgery, which, in Brazil, was limited to thoracoplasty to treat tuberculosis. He visited Dr Evarts Graham in St. Louis, at Barnes Hospital, who had performed the world's first pneumonectomy for lung cancer. Through the Brazil-USA Cultural Union and the Institution of International Education, Zerbini applied for a scholarship from the US State Department. He received the award on January 17, 1944, and 6 months later, went to the United States for an initial period of 1 year. At Barnes Hospital, surrounded by the leaders of his specialty at the time and having at his disposal the latest surgical technology available, Zerbini felt as if he were in another world. He encountered little competition from American residents, because most young physicians had been drafted into the Armed Forces during the Second World War.

Having completed 6 months at Barnes Hospital, Zerbini moved to Boston where he remained for an additional semester under the guidance of Professor Oliver Cope at the Massachusetts General Hospital. Between July and September 1945, Zerbini visited various departments of surgery including that of Dr Alfred Blalock in Baltimore. The knowledge Zerbini brought back with him on his return to Brazil was to become the beginning of Brazilian heart surgery.

Once back in Brazil, Zerbini performed the second Blalock-Taussig procedure in that country, the first onebeing performed by Domingos Pinto who had trained under Dr Charles Bailey. Zerbini also performed the first ligation of a patent ductus arteriosus in an 18-year-old man. He was also the first surgeon in Brazil to repair coarctation of the aorta. In 1952, he initiated the use of hypothermia to treat simple congenital problems such as atrial septal defects.

Zerbini married a physician, Dirce Costa, on January 24, 1949. To learn about the new heart-lung machine, he visited Dr Lillehei with his wife and students, Adib Jatene, Delmont Bittencourt, and Geraldo Viginelli. Zerbini initiated his studies leading to the use of extracorporeal circulation in Brazil. Clinical cardiac operation using the heart-lung machine was begun by Zerbini only 1 year after the pioneering work of Dr Hugo Felipozzi, who performed the first such operation in Brazil [2].

In 1958, at the São Paulo University Hospital, Zerbini began to devote his efforts to correction of Tetralogy of Fallot. Ten years later, Zerbini became the Chair of Cardiothoracic Surgery, presenting a dissertation in which he analyzed 103 of his personal 480 Tetralogy of Fallot repairs. In 1969, the American Association for Thoracic Surgery invited Zerbini to give the honored guest lecture on the subject "The surgical treatment of Fallot complex: late results" [3].

During that time, Zerbini, who was familiar with the treatment of mitral stenosis with closed commissurotomy, learned that open mitral commissurotomy had been introduced in the United States. Applying this new technique, Zerbini presented his results of open mitral commissurotomy in a meeting in Mexico. He was criticized and told "there are things in life that it is better to enjoy with the eyes closed."

Although new "open" operations allowed for treatment of different pathologies of the heart, approximately $30 \%$ of the patients died postoperatively. Zerbini assigned the task of identifying the etiology of this high mortality to Rui Gomide. From their studies, they found that the mortality was due to acid-base disturbances caused by extracorporeal circulation. It was then that Zerbini acquired the first $\mathrm{pH}$ meter in Brazil.

Surgical techniques for occlusive coronary artery disease began in Brazil in 1960 with the Vineberg operation being performed mainly in São Paulo and Rio de Janeiro. Within a year of Rene Favaloro performing the first direct coronary bypass at the Cleveland Clinic, Jatene began using this technique in Brazil; Zerbini, Waldir Jazbik, and Domingos de Moraes soon followed suit.

In the early 1960s, the first artificial heart valves became available. Several prostheses were used during this period and Zerbini managed to import some of these valves. Adib Jatene, in the São Paulo Institute of Cardiology, manufactured a caged-ball prosthesis [4]. Also, at the São Paulo Hospital, the workshop producing heart-lung machines developed an assembly line for the manufacture 
of prosthetic valves. By mid-1965, 300 Brazilians were already living with implanted, Brazilian-made heart valves.

Mechanical valves and the need for anticoagulation posed a special problem for a population with low socioeconomic and cultural resources. The homologous dura mater valve, introduced in 1971 by Puig, Viginelli, and Zerbini, gained quick acceptance and was used extensively at the time by surgeons throughout the country and abroad [5]. Unfortunately, the valve was subsequently discontinued because of structural defects and logistic problems. Nonetheless, the initial impetus was important in that it made possible for the development of cardiac valves in Brazil. In accordance with Zerbini's hopes, Brazil today has several laboratories producing valves of excellent quality such as the Braile Biomédica, Biocor, Labcor, and others.

The first human heart transplant was performed by Christian Barnard on December 4, 1967, in Cape Town, South Africa. Zerbini learned of the transplant from newspapers the next day. Heart surgeons the world over felt personally challenged to emulate the gigantic step taken by Barnard. Zerbini, anxious to be among the first in the world to embrace this new phase of heart operations, performed the first heart transplant in Brazil on May 25, 1968, only 6 months after Barnard's groundbreaking procedure. From then on Zerbini received national and international recognition and became a national celebrity. When it was announced that the world's 17 th heart transplant had been performed successfully in Brazil, an atmosphere of civic joy was generated, and Zerbini became a national idol. He was honored by ordinary people, official bodies, state governors, and the President of Brazil. On September 26, 1968, Zerbini successfully performed his second heart transplant.

\section{The New Phase in Cardiac Operations}

In his commitment to bring the latest in technology and bioengineering to Brazil, Zerbini had formed a team composed of surgeons including his wife, Delmont Bittencourt, Geraldo Verginelli, and Adib Jatene, as well as Dagoberto S. Conceição, Rubens Monteiro de Arruda, Domingo Marcolino Braile, Antonio Geraldo de Freitas Netto, Euclides Marques, Seigo Tsuzuki, Noedir Stolf, Otoni Gomes, Miguel Barbero-Marcial, Sergio Almeida de Oliveira, Luiz Boro Puig, Magnus Rosa C. de Sousa, and Ruy Gomide do Amaral (anesthesiologist) to help in advancing cardiac surgery in Brazil [6]. Initially, most of the cases were congenital heart procedures such as closure of atrial and ventricular septal defects. Acquired adult heart procedures were slower to develop.

From the outset, Zerbini believed that Brazil could not afford to import all of the materials needed to develop the technology for the heart-lung machine. His disciples Domingo M. Braile, Dirce Costa Zerbini, Seigo Tsuzuki, Otoni
Moreira Gomes, and Adib D. Jatene in São Paulo, interacting with Domingos J. Moraes, Waldyir Jazbik, and Marcos Cunha in Rio de Janeiro, lead Brazil to become a major center for the production of medical products for use nationally.

At Zerbini's invitation, Brazil was visited at the time by many famous surgeons. Denton Cooley noted that when he first came to Brazil in 1959, he had personally performed 500 open mitral commisurotomies; Zerbini had only begun his experience. By the time Cooley returned in 1962, he was surprised with the number of operations conducted by Zerbini.

Zerbini was invited to make surgical demonstrations in various regions of Brazil and throughout South America; he took his surgical team and all necessary equipment including a blood bank with him. Doing so, he was then able to perform heart operations "away from home." This helped disseminate and demystify heart operations to the most distant parts of the country. In 1962, for example, the city of Curitiba with Iseu Affonso da Costa at the Hospital das Clínicas of the Federal University of Paraná, and the city of Recife with Luis Tavares da Silva at the Hospital Pedro II- Federal University of Pernambuco, became the first cities outside the Rio de Janeiro-São Paulo axis where cardiac operations were performed using extracorporeal circulation. In 1963, a small city in São Paulo state, São José do Rio Preto, proved to Brazil that Zerbini's school yielded fruits. The first center of heart surgery in a remote area of the country was created, demonstrating that the simplification introduced by Zerbini would allow most Brazilian cities to have the resources to perform cardiac operations. One of his most outstanding disciples, Professor Costabile Gallucci eventually would create the cardiovascular center at the Escola Paulista de Medicina. This institution became famous because of the work of Enio Buffolo, one of the pioneers in off-pump coronary artery operations.

Once extracorporeal circulation became routine, São Paulo city continued to maintain the leadership within Brazil, becoming the source from which most Brazilian graduates of the department of surgery would originate. The volume of cardiac operations performed was impressive, attaining levels comparable to those of other major centers of in Europe and the United States. Nearly 400 Brazilian and South American heart surgeons learned their specialty from Zerbini.

\section{The Final Phase of Zerbini's Life}

After mandatory retirement from the University at the age of 70, Zerbini continued to work until his death. In the last 10 years of his life his influence, prestige, and productivity continued as before. Among his legacies, perhaps the most notable in South America are the Heart Institute (INCOR) of the University of São Paulo and the Sociedade Brasileira de Cirurgia Cardiovascular (SBCCV). 
Also, at São Paulo's Portuguese Beneficient Hospital, 10 independent teams of cardiac surgeons, all former students of Zerbini, perform about six operations per team per day, representing an average of 60 operations per day, more than 1,200 operations per month, and 15,600 heart operations per year. Most likely, these teams perform the highest number of heart procedures per year in the world.

Because of the impact of the first heart transplant, Zerbini was able to take advantage of the fame and political prestige that he had acquired to develop INCOR, an institute devoted exclusively to the treatment of diseases of the heart. Getting the institute to function was achieved in 1977 with the creation of the E.J. Zerbini Foundation, which transformed INCOR into a model institution whose efficiency is a paradigm in the field of health care in South America.

Concerned about the union and development of cardiac surgery in Brazil, in 1970 Zerbini founded the SBCCV, of which he was the first president. This SBCCV now has more than 700 members and is responsible for board certification of cardiac surgeons. While Zerbini was still alive, the Sociedade dos Discipulos do Professor Zerbini was created. This Society continues to meet yearly honoring his teaching, honesty, and hard work.

Everything that Zerbini did, he did well. He gave his all and demonstrated that serious and tenacious work never fails to bear fruit. "Omnia vincit labor" (nothing surpasses work) was Zerbini's first and most repeated teaching to motivate his disciples with the powerful example of his own life.

\section{REFERENCES}

1. Araujo CA. Dr. Zerbini: O operário do coração. São Paulo: Bandeirante; 1988. p.220.

2. Iseu A. Costa: História da cirurgia cardíaca Brasileira, 1st ed. São Paulo: Sociedade Brasileira de Cirurgia Cardiovascular; 1966. p.186.

3. Zerbini EJ. The surgical treatment of the complex of Fallot. J Thorac Cardiovasc Surg. 1969;58(2):158-77.

4. Zerbini EJ, Bittencourt D, Pileggi F, Jatene A. Surgical correction of aortic and mitral lesions. Results in a series of 105 patients who underwent a valvular replacement with the Starr prosthesis. J Thorac Cardiovasc Surg. 1966;51(4):474-83.

5. Puig LB, Verginelli G, Belotti G, Kawabe L, Frack CC, Pileggi F, et al. Homologous duramater cardiac valve. Preliminary study of 30 cases. J Thorac Cardiovasc Surg. 1972;64(1):154-60.

6. Gomes OM, Conceição DS, Nogueira D Jr, Tsuzuky S, Bittencourt D, Zerbini EJ. Variable-column buble oxygenation. A new system for bubble oxygenation. J Thorac Cardiovasc Surg. 1975;69(4):606-14.

Artigo publicado originalmente no The Annals of Thoracic Surgery, volume 72(5), páginas 1789-92. 2001. Reproduzido com permissão. Copyright Clearance Center - License Date: Feb 1, 2012. License Number: 2840281196845. 